\title{
c-Met responsiveness of isolated hepatocytes evaluated in an in vitro de-differentiation model
}

\author{
KIM A. BOOST ${ }^{1}$, HE-JIN KIM ${ }^{2}$, TOBIAS ENGL ${ }^{2}$, ELSIE OPPERMANN ${ }^{2}$, \\ DIETGER JONAS ${ }^{2}$, ANTON OERTL $^{2}$ and ROMAN A. BLAHETA ${ }^{2}$ \\ ${ }^{1}$ Klinik für Anästhesiologie, Intensivmedizin und Schmerztherapie, ${ }^{2}$ Klinik für Urologie und Kinderurologie, \\ Zentrum der Chirurgie, Johann Wolfgang Goethe-Universität, Frankfurt am Main, Germany
}

Received August 8, 2005; Accepted September 16, 2005

\begin{abstract}
Hepatocyte growth factor (HGF) accelerates tissue regeneration and ameliorates tissue fibrosis through its ligand c-Met receptor tyrosine kinase. Hence, HGF is currently discussed as an attractive therapeutic candidate for fatal liver diseases. However, it remains unclear whether c-Met of dedifferentiated hepatocytes adequately responds to HGF in an impaired liver. Therefore, we investigated c-Met expression and c-Met responsiveness to HGF in an experimental dedifferentiation cell culture system. Primary rat hepatocytes were seeded on a two-dimensional collagen matrix or embedded within a three dimensional collagen gel to guarantee intact cell geometry. Cells were cultivated in a growth factor enriched extracellular milieu (de-differentiation medium), or in a chemically defined differentiation medium, representing physiologically intact hepatocytes. c-Met surface expression was determined by flow cytometry. Receptor localisation was examined by confocal microscopy, c-Met and phosphorylated c-Met protein were determined by Western blotting. Hepatocyte-specific asialoglycoprotein receptor (ASGPr) was examined to control the differentiation status of the cells. Growth factor enriched milieu induced a rapid loss of ASGPr with a significant increase of c-Met surface level and a decrease in c-Met protein level. Surprisingly, the increased amount of c-Met surface expression was associated with its loss of responsiveness to HGF. The addition of bile acids into the culture medium had significantly delayed the process of de-differentiation and restrained the drastic elevation of c-Met (tauroursodeoxycholic acid $>$ ursodeoxycholic acid). Application of the three-dimensional hepatocellular architecture stabilized the c-Met surface receptor level and rendered c-Met
\end{abstract}

Correspondence to: Dr Roman Blaheta, J.W. Goethe-Universitätsklinik, Zentrum der Chirurgie, Klinik für Urologie und Kinderurologie, Interdisziplinäres Forschungs- und Laborgebäude, Haus 25, Raum 204, Theodor-Stern-Kai 7, D-60590 Frankfurt am Main, Germany

E-mail: blaheta@em.uni-frankfurt.de

Key words: ASGPr, cirrhosis, c-Met, de-differentiation, hepatocytes activation. We have demonstrated that growth factor enriched extracellular milieu and loss of intact liver architecture seems to be accompanied by an up-regulation of c-Met surface level. Our findings suggest that irresponsiveness of c-Met to soluble HGF was possibly caused by an excessive HGF production and receptor over-stimulation. Both events should be considered when establishing an HGF-based therapy for fibrosis/cirrhosis.

\section{Introduction}

Liver cirrhosis, which is usually a long-term consequence of chronic hepatic injury caused by alcohol abuse or hepatitis virus infection, is characterized by extensive fibrous scarring of the liver. Advanced cirrhosis is generally irreversible and is often associated with variceal hemorrhage or development of hepatocellular carcinoma. Hence, liver cirrhosis is a major cause of morbidity and mortality worldwide.

An effective treatment, capable of counteracting cirrhosis, has not yet been developed. Hypothetically, therapeutic strategies must rely on achieving liver regeneration and increased extracellular matrix degradation (1).

Hepatocyte growth factor (HGF), originally identified and cloned as a mitogenic protein for hepatocytes, exerts diverse cellular responses through c-Met receptor tyrosine kinase $(2,3)$. HGF is a pluripotent growth factor displaying a remarkable ability to promote tissue repair and organ regeneration after injury (4). HGF is a potent agent for acceleration of tissue regeneration following an acute insult, as well as amelioration of tissue fibrosis and dysfunction in chronic conditions (5-7).

Based on the trophic roles of HGF in tissue regeneration and protection, HGF is currently discussed as an attractive therapeutic agent for fatal liver diseases. Approaches to address the therapeutic potential of HGF have already been made using a variety of experimental models, and indeed there are promising results that administration of HGF leads to improvement in hepatic cirrhosis $(8,9)$.

Nevertheless, although the concept of therapeutical HGF application might be plausible, studies have also shown that a cirrhotic liver following hepatic resection regenerates very slowly in comparison with a normal liver (10-12). This might be in contradiction to the statements given above, as HGF has been found to be excessively increased in the cirrhotic 
liver $(13,14)$. It therefore seems to be unclear why external supplements of HGF should lead to recovery from cirrhosis.

We speculated that c-Met receptors might not respond adequately to HGF in the cirrhotic liver. To verify this, c-Met expression and HGF-induced phosphorylation were analyzed using hepatocytes cultured under de-differentiation inducing conditions, i.e. in a growth factor enriched extracellular milieu. A characteristic feature of fibrosis/cirrhosis is disturbance of the liver architecture. To mimic this process, we compared hepatocytes with an intact three-dimensional architecture to those plated on a two-dimensional matrix.

\section{Materials and methods}

Isolation of rat hepatocytes. The study protocol was approved by the local ethics committee and the governmental board for the care of animal subjects (Regierungspräsidium Darmstadt, Germany). Primary hepatocytes were isolated from livers of male Sprague-Dawley Rats (body weight: 400-500 g). Isolation of hepatocytes was performed by a two-step collagenase perfusion technique as previously described (16). Briefly, the portal vein was flushed for 15-20 min with EGTA-solution (HBSS w/o $\mathrm{Ca}^{2+}$ and $\mathrm{Mg}^{2+}, 0.5 \mathrm{mM}$ EGTA) at $37^{\circ} \mathrm{C}$, at a flow rate which was increased from $20 \mathrm{ml} / \mathrm{min}$ to $40 \mathrm{ml} / \mathrm{min}$ (Masterflex pump, Novodirekt, Kehl am Main, Germany). The liver was then perfused under recirculation with collagenasesolution (HBSS w/o Ca ${ }^{2+}$ and $\mathrm{Mg}^{2+}, 5 \mathrm{mM} \mathrm{CaCl} 2,0.075 \%$ collagenase type IV) at the same temperature, at a flow rate which was increased from 40 to $80 \mathrm{ml} / \mathrm{min}$ (incubation: 10-30 min).

At the end of the perfusion, the non-perfused part of the liver tissue was discarded and liver cells from the well-perfused part were scraped out and gently dispersed in cold HBSS, enriched with $10 \%$ HEPES-buffer and $50 \mu \mathrm{g} / \mathrm{ml}$ gentamycin. The cell suspension was filtered through a $70-\mathrm{mm}$ nylon mesh filter and centrifuged at $28 \mathrm{~g}(5 \mathrm{~min})$. The pellet was resuspended in DMEM/Ham's F12 medium and overlayed onto Percoll gradient with a density of $1.065 \mathrm{~g} / \mathrm{ml}$ (Percoll, Pharmacia), followed by low speed Bouyant-gradient centrifugation of the liver-cell-suspension at $50 \mathrm{x} \mathrm{g}$.

The cell-isolation yielded a mean number of $2.3 \times 10^{8}$ primary rat hepatocytes (HC) (minimum $2.8 \times 10^{6}$, maximum $4.6 \times 10^{8} \mathrm{HC}$ ) with a cell viability of $89 \pm 9 \%$, measured by trypan-blue dye exclusion. Isolated hepatocytes were resuspended in complete culture medium, described elsewhere, and seeded at a final density of $1.8 \times 10^{5}$ cells $/ \mathrm{cm}^{2}$ into multi-well plates coated with extracellular matrices to enable confluent monolayers.

Preparation of two-dimensional collagen matrix. Each well was coated with $25 \mu \mathrm{g} / \mathrm{cm}^{2}$ of Collagen type I, derived from bovine skin (Seromed-Biochrom, Berlin, Germany). After incubation for $1 \mathrm{~h}$ at $37^{\circ} \mathrm{C}$, each well was washed twice with PBS (Gibco) before plating the hepatocytes.

Preparation of sandwich-cultured hepatocytes. To prepare a three-dimensional collagen gel configuration (3D gel), the culture medium was removed after $24 \mathrm{~h}\left(37^{\circ} \mathrm{C}, 5 \% \mathrm{CO}_{2}\right)$ and replaced by the collagen-sandwich-solution. The collagen sandwich solution was prepared by diluting 1 part $10 \mathrm{X}$
Dulbecco's modified Eagle's medium (DMEM) and 1 part $0.1-0.2 \mathrm{M} \mathrm{NaOH}$ in 10X HEPES buffer in 8 parts of collagen I $(3 \mathrm{mg} / \mathrm{ml})$. The collagen overlays were incubated for $6 \mathrm{~h}$ $\left(37^{\circ} \mathrm{C}, 5 \% \mathrm{CO}_{2}\right)$ to allow collagen to gel before the addition of hepatocyte culture medium. The culture medium was changed after the first $24 \mathrm{~h}$ and thereafter every $48 \mathrm{~h}$.

Composition of the culture media and hepatocyte incubation. Hepatocytes were cultured continuously either in a differentiation medium representing physiologically healthy hepatocytes, or cultivated in a de-differentiation medium, an enriched extracellular milieu which occurs during cirrhotic processes. Initiation of this culture system and the relevance of the medium composition for the hepatocellular differentiation status have been described in detail in the previous report (17).

Both media consisted of DMEM (Invitrogen, Karlsruhe, Germany), supplemented with $5 \%$ pooled human serum (kindly provided by the blood bank of the Red Cross, Frankfurt, Germany), $20 \mathrm{mM}$ HEPES, and $50 \mu \mathrm{g} / \mathrm{ml}$ gentamycin (Gibco/ BRL, Karlsruhe, Germany). Differentiation medium was enriched with nicotinamide, insulin, transferrin, selenium, and dexamethasone. De-defferentiation medium was deprived of hormones but instead enriched with the mitogens, EGF, HGF, and granulocyte-macrophage colony-stimulating factor (GM-CSF). The full description of both media is shown in Table I.

Ursodeoxycholic acid and tauroursodeoxycholic acid were obtained from Falk, Freiburg, Germany and added to a specified culture medium.

Analysis of surface c-Met and ASGPr expression by flow cytometry. Hepatocyte-specific ASGPr was necessary to control the differentiation status of the cells $(15,19)$. For the analysis of c-Met receptor, hepatocytes were washed in PBS without $\mathrm{Ca}^{2+}$ or $\mathrm{Mg}^{2+}$ followed by 5-10-min incubation with ice-cold $0.02 \%$ EDTA solution (Seromed/Biochrom). The detached $\mathrm{HC}$ was centrifuged at $250 \mathrm{x}$ g for $5 \mathrm{~min}$, cell pellets were incubated with diluted anti c-met (rabbit, polyclonal, 1:100; Santa Cruz Biotechnology, Heidelberg, Germany) in PBS with $0.5 \% \mathrm{BSA}$ for $60 \mathrm{~min}$ at $4^{\circ} \mathrm{C}, \mathrm{HC}$ were washed after incubation and further labeled with goat anti-rabbit FITC-IgG (Dianova; 1:50) in PBS, 0.5\% BSA for $30 \mathrm{~min}$ at $4^{\circ} \mathrm{C}$. For ASGPr analysis, HC were treated with Fix\&Perm kit (An der Grub/Dianova, Hamburg, Germany) prior to intracellular staining. The detached $\mathrm{HC}$ were fixed with reagent $\mathrm{A}$ for $10 \mathrm{~min}$, washed and incubated with reagent $\mathrm{B}$ together with diluted anti-ASGPr (rabbit, polyclonal, 1:100; kindly provided by U. Treichel, Essen) in PBS with $0.5 \%$ BSA for $60 \mathrm{~min}$ at $4^{\circ} \mathrm{C}$. HC were washed and incubated for $30 \mathrm{~min}$ at $4^{\circ} \mathrm{C}$ with reagent $\mathrm{B}$ together with goat anti-rabbitFITC-IgG (Dianova; 1:50) in PBS with $0.5 \%$ BSA. After extensive washing, immnunofluorescence was analyzed by a FACScan Flow cytometer (Becton-Dickinson, Heidelberg, Germany) using cellquest software. The receptor expression is given as MFI (Mean Fluorescence Intensity) [FL-1H (log) channel histogram analysis; $1 \times 10^{4}$ cells/scan].

Western blot analysis. Hepatocyte cultures were rinsed briefly with ice-cold PBS and lysed for $5 \mathrm{~min}$ in lysis buffer $(50 \mathrm{mM}$ HEPES, $200 \mathrm{mM} \mathrm{NaCl}, 0.2 \mathrm{mM} \mathrm{MgSO}_{4}$ (Merck), $0.4 \mathrm{mM}$ 
Table I. Cell culture media.

\begin{tabular}{|c|c|c|}
\hline & $\begin{array}{l}\text { Differentiation } \\
\text { medium }\end{array}$ & $\begin{array}{c}\text { De-differentiation } \\
\text { medium }\end{array}$ \\
\hline & DMEM & DMEM/Ham's F12 \\
\hline & $20 \mathrm{mM}$ HEPES & $20 \mathrm{mM}$ HEPES \\
\hline & $50 \mu \mathrm{g} / \mathrm{ml}$ & $50 \mu \mathrm{g} / \mathrm{ml}$ \\
\hline & gentamycin & gentamycin \\
\hline & $5 \%$ human serum & $5 \%$ human serum \\
\hline & & $10 \mathrm{ng} / \mathrm{ml} \mathrm{EGF}$ \\
\hline & & $1 \mathrm{ng} / \mathrm{ml} \mathrm{HGF}$ \\
\hline & & $1 \mathrm{ng} / \mathrm{ml} \mathrm{GM-CSF}$ \\
\hline D-glucose & $2 \mathrm{~g} / 1$ & $3.15 \mathrm{~g} / 1$ \\
\hline Galactose & $2 \mathrm{~g} / 1$ & \\
\hline Ornithine & $0.1 \mathrm{~g} / 1$ & \\
\hline L-proline & $0.03 \mathrm{~g} / 1$ & $0.02 \mathrm{~g} / 1$ \\
\hline Nicotinamide & $305 \mathrm{mg} / \mathrm{l}$ & $2.02 \mathrm{mg} / \mathrm{l}$ \\
\hline $\mathrm{ZnCl}_{2}$ & $0.544 \mathrm{mg} / 1$ & \\
\hline $\mathrm{ZnSO}_{4} 7 \mathrm{H}_{2} \mathrm{O}$ & $0.75 \mathrm{mg} / \mathrm{l}$ & $0.432 \mathrm{mg} / \mathrm{l}$ \\
\hline $\mathrm{CuSO}_{4} 5 \mathrm{H}_{2} \mathrm{O}$ & $0.2 \mathrm{mg} / \mathrm{l}$ & $0.0013 \mathrm{mg} / \mathrm{l}$ \\
\hline $\mathrm{MnSO}_{4}$ & $0.025 \mathrm{mg} / \mathrm{l}$ & \\
\hline L-glutamine & $580 \mathrm{mg} / \mathrm{l}$ & $365 \mathrm{mg} / \mathrm{l}$ \\
\hline ITS $^{\mathrm{a}}$ & $0.5 \mathrm{~g} / 1$ & \\
\hline Dexamethasone & $1.0 \mathrm{~g} / 1$ & \\
\hline
\end{tabular}

aTS: rh-insulin $5.0 \mathrm{mg} / \mathrm{l}$, human transferrin $5.0 \mathrm{mg} / \mathrm{l}$, selenium $5.0 \mu \mathrm{g} / 1$.

PMSF, 2\% Triton-X-100, $10 \mu \mathrm{g} / \mathrm{ml}$ leupeptine, $10 \mu \mathrm{g} / \mathrm{ml}$ aprotinine, $0.02 \%$ soybean-trypsin-inhibitor, and $0.2 \mathrm{mM}$ ortho-vanadate (all Sigma-Aldrich). The cell lysates were centrifuged for $10 \mathrm{~min}$ at $12.000 \mathrm{U} / \mathrm{min}$ at $4^{\circ} \mathrm{C}$. The protein concentrations of supernatant were determined by the Lowry method, and equal amounts of protein $(50 \mu \mathrm{g})$ in laemmli sample buffer (Bio-Rad Laboratories) with ß-mercaptoethanol were boiled for $5 \mathrm{~min}$. Proteins and molecular weight marker were resolved by $7 \%$ sodium dodecyl sulfate (SDS)-polyacrylamide gel (90 $\mathrm{min}, 100 \mathrm{~V})$ and then electroblotted to nitrocellulose membranes. Membranes were blocked for $1 \mathrm{~h}$ at RT with $10 \%$ dry non-fat milk in Tris-buffered saline and incubated with primary antibodies: anti-c-Met (rabbit, polyclonal, Santa Cruz Biotechnology, Heidelberg, Germany) and anti-ASGPr (rabbit, polyclonal, kindly provided by U. Treichel, Essen) overnight at $4^{\circ} \mathrm{C}$. Both antibodies were diluted to $1: 100$ in Tris-buffered saline with $0.5 \%$ BSA. Membranes were washed and labeled with horseradish peroxidase (HRP)-conjugated secondary antibodies, goat anti-rabbit-IgG (1:5000, Biozol). Immunoreactivity was detected using a chemiluminescence Western blotting system (Chemiluminescence Detection kit, Amersham).

Receptor phosphorylation. Hepatocytes were maintained in serum and HGF/EGF-free DMEM F-12 for $24 \mathrm{~h}$ prior to stimulation in order to avoid any artefacts of protein phosphorylation due to serum and growth factors. Hepatocytes were stimulated for 3 min with $1 \mathrm{ng} / \mathrm{ml}$ HGF (R\&D Systems, Wiesbaden, Germany). Subsequently, hepatocytes were rinsed with ice-cold PBS, lysed for $5 \mathrm{~min}$ in lysis buffer, and Western blot assay was carried out as described above. The monoclonal antibody, p-Tyr (Santa Cruz Biotechnology; clone PY99, 1:250 dilution), was used to detect ligandinduced tyrosine phosphorylation. The EGFr and c-Met expressing cell line, A431, served as the positive control.

Confocal laser-scanning microscopy. Hepatocytes were plated on 12-mm round cover slips (pretreated with collagen I) overnight. Cells were then washed and fixed with $-20^{\circ} \mathrm{C}$ methanole/ acetone ( $\mathrm{V} / \mathrm{V} 60 \% / 40 \%)$ followed by incubation on ice for $60 \mathrm{~min}$ with unconjugated antibody rabbit anti-c-Met (1:100, rabbit, polyclonal; Santa Cruz Biotechnology). Cells were washed twice before incubation with $\mathrm{Cy} 3$-conjugated goat anti-rabbit-IgG (1:50, Dianova) for $30 \mathrm{~min}$ on ice. To prevent photobleaching of the fluorescent dye, stained cells were mounted on slides with anti-fading reagent kit (ProLong ${ }^{\text {TM }}$ Antifade Kit, MoBiTec, Göttingen, Germany). The slides were viewed using a confocal laser scanning microscope (LSM 10; Zeiss, Jena, Germany) with a planneofluor x100/1.3 oil immersion objective.

Statistical analysis. Data are expressed as mean \pm SD. All experiments were performed 3-6 times. Statistical significance was investigated by the Wilcoxon-Mann-Whitney U test. Differences were considered statistically significant at $\mathrm{p}<0.05$.

\section{Results}

Cirrhosis is accompanied by hepatocyte de-differentiation and c-Met elevation. Hepatocytes that were cultivated on a two-dimensional collagen matrix in a differentiation medium generated a constant ASGPr level, which implies that cells remained differentiated throughout the period of experiment (Fig. 1A). Additionally, the c-Met surface level did not change during the evaluation period (Fig. 1B). Confocal analysis showed homogeneous distribution of localized ASGPr and c-Met receptors (Fig. 3). Western blot analysis revealed equal amounts of ASGPr and c-Met proteins, even until day 5 of cell cultivation (Fig. 2), contrary to the hepatocytes in a dedifferentiation medium, which resulted in a rapid loss of ASGPr, indicating the de-differentiation stage (Figs. 1A and 2). Elevation of c-Met surface level was accompanied by a reduction in intracellular c-Met protein content (Figs. 1B and 2).

To prove that the c-Met increase was indeed caused by soluble HGF, hepatocytes were cultivated under serum and HGF-free conditions and then activated by different concentrations of HGF, which was applied exogenously. Fig. 4 shows HGF-dependent c-Met up-regulation, whereby the amount of c-Met surface level correlated positively with the HGF concentration used.

Ursodeoxycholic and tauroursodeoxycholic acid protect hepatocytes from de-differentiation. Culturing hepatocytes in a cirrhosis representing milieu enriched with ursodeoxy- 
A

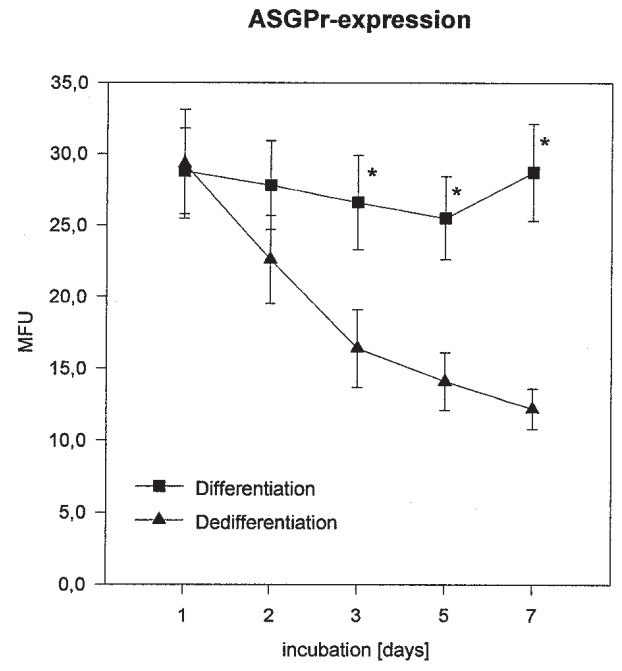

B

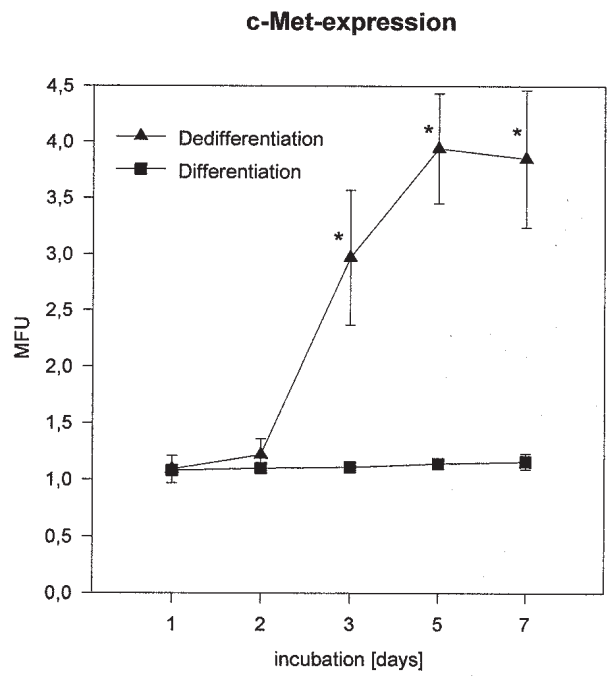

Figure 1. Analysis of surface ASGPr- (A) and c-Met-expression (B). Hepatocytes were cultured on a two-dimensional collagen matrix either in chemically defined differentiation medium or in de-differentiation medium representing cirrhotic conditions. The surface receptor level was detected by flow cytometry and expressed as mean fluorescence units (MFU). Each symbol represents mean values \pm SD of $n=6$ experiments. Evaluation of fluorescence was carried out on days $1,3,5$ and 7 after plating the cells. *Statistically significant differences.

\section{Two-dimensional culture system}

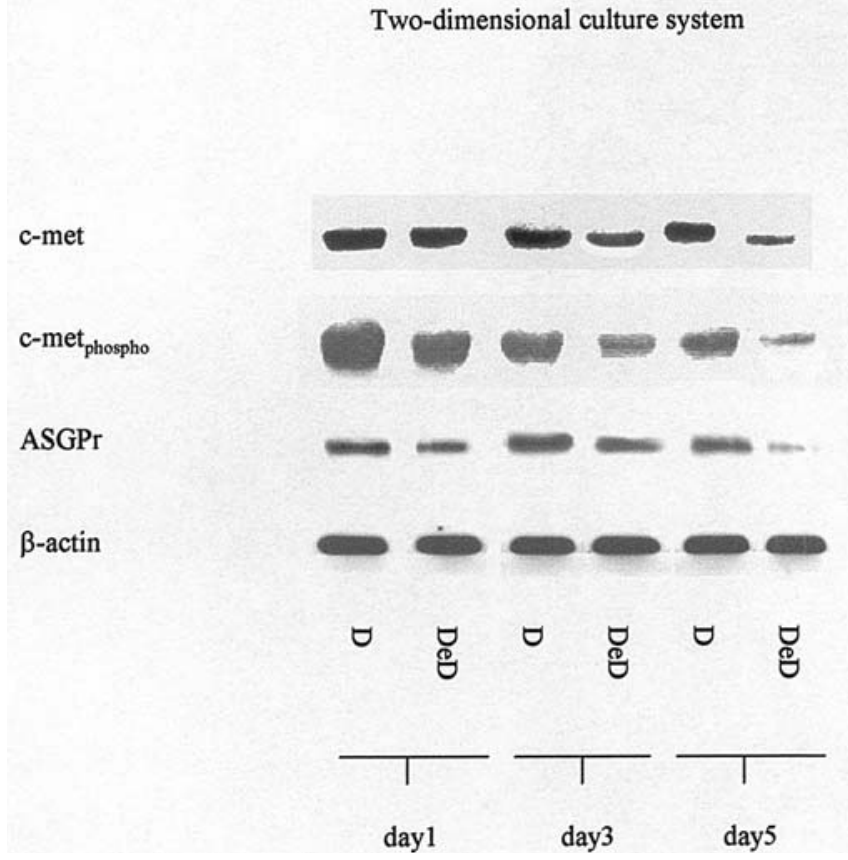

Figure 2. Western blot analysis of c-Met, ASGPr and phosphorylated c-Met protein content. Hepatocytes were incubated on a two-dimensional collagen matrix either in chemically defined differentiation medium or in dedifferentiation medium representing cirrhotic conditions. The protein content was analyzed on day 1,3 or 5 after plating the hepatocytes. D, cultivation in differentiation medium; DeD, cultivation in de-differentiation medium. B-actin served as the internal control. The figure shown is representative of three separate experiments.

cholic or tauroursodeoxycholic acid significantly delayed the progression of hepatocyte de-differentiation (Fig. 5). Tauroursodeoxycholic acid exerted stronger effects than ursodeoxycholic acid. Most impressively, the addition of tauroursodeoxycholic acid to the culture medium completely prevented the loss of ASGPr which was observed when hepatocytes were incubated in de-differentiation medium alone (Fig. 5A). c-Met expression was altered only moderately under tauroursodeoxycholic acid (Fig. 5B). Control experiments had been carried out in a normal milieu representative of a non-impaired liver, both ursodeoxycholic or tauroursodeoxycholic acid did not influence any changes in ASGPr and c-Met expression (data not shown).

Up-regulation of c-Met is accompanied by receptor nonresponsiveness. Although the c-Met receptor was expressed very highly along the cell surface, it remained incapable of responding to soluble HGF. Fig. 2 demonstrates that c-Met lost the ability to become activated over time when hepatocytes were cultivated in a de-differentiation medium. Therefore, we prioritized an HGF-free environment (differentiation medium) to allow receptor phosphorylation (Fig. 2).

A three-dimensional hepatocyte architecture promotes cell differentiation and $c$-Met responsiveness. Cirrhosis is accompanied by distinct alterations in liver geometry. We analyzed if hepatocyte polarity contributes to cellular differentiation and c-Met responsiveness. Our results indeed showed that the ASGPr expression level remained constant over three days. Hepatocytes that were allowed to reorientate threedimensionally in a growth factor enriched extracellular environment (de-differentiation medium; Fig. 6A) elicited a gradual reduction of ASGPr, in contrast to our observation in a two-dimensional collagen matrix, where a rapid loss of ASGPr was generated. A similar effect was also detected with ASGPr protein (Fig. 6A). Therefore, the data indicate that at least a transient stabilization of the differentiation status is achieved in polar hepatocytes. 


\section{c-met localization}

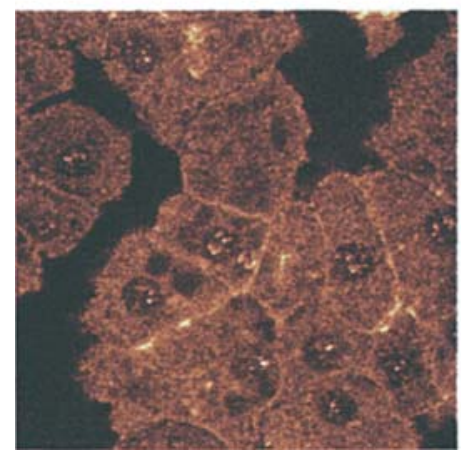

ASGPr localization

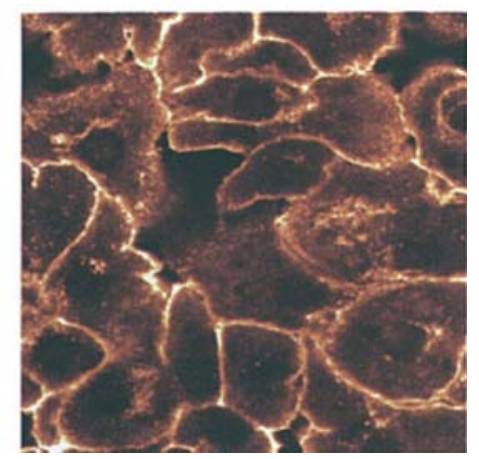

Figure 3. Confocal images of the distribution pattern of ASGPr and c-Met receptor molecules on freshly isolated hepatocytes. Indocarbocyanine staining, $\mathrm{x} 100 / 1.3$ oil immersion objective.

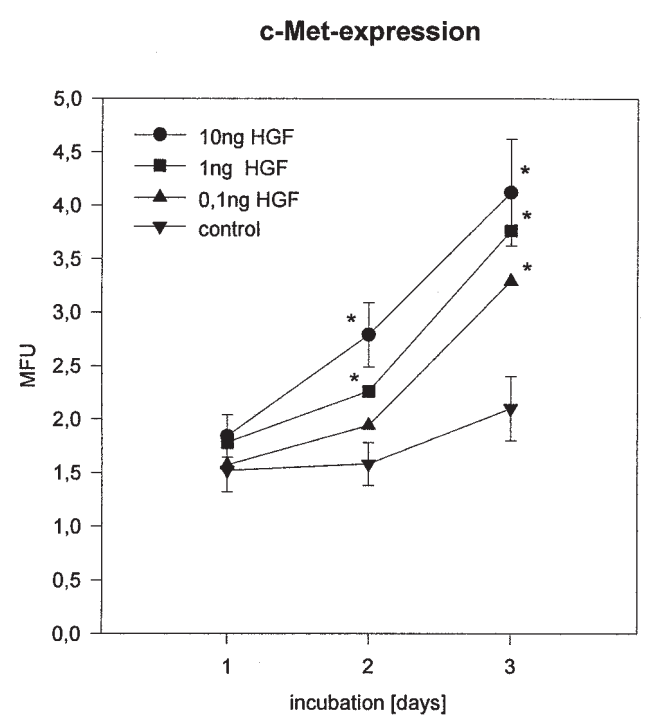

Figure 4. Dose-response analysis of c-Met expression in hepatocytes. Hepatocytes were seeded on a two-dimensional collagen matrix, incubated in an HGF and serum-free culture medium and then activated by various $\mathrm{HGF}$ concentrations ranging from 0.1 to $10 \mathrm{ng} / \mathrm{ml}$. The receptor level was detected by flow cytometry and expressed as mean fluorescence units (MFU). Mean \pm SD of $n=6$ experiments is shown. Receptor evaluation was carried out on days 1, 2 and 3 after plating. "Significant differences to unstimulated controls.

The same phenomenon was observed with respect to c-Met. Both c-Met surface level and intracellular c-Met protein content did not change dramatically over a period of time in a threedimensional culture system (Figs. 6B and 7).

The monoclonal antibody, p-Tyr, was used to detect ligand induced tyrosine phosphorylation. Interestingly, hepatocytes preserved their sensitivity to soluble HGF when threedimensional cell morphology was established, even under dedifferentiation inducing conditions (Fig. 7).

\section{Discussion}

Proper liver architecture is crucial for hepatic function but is commonly disrupted in cirrhosis. In a liver cirrhosis model, marked and widespread signs of dysplasia, with nuclear pleomorphisms and initial loss of normal architecture were scored in mice exposed to ethanol but not in the control group (18). The disturbance of architecture was accompanied by a progressive cellular de-differentiation, as revealed by an increase in gene expression for alpha-fetoprotein, hepatocyte growth factor, and c-myc (19). Notably, c-Met receptor expression was detected in activated hepatic stellate cells while receptors remained undetectable in normal tissue (8).

Our experiment demonstrates that a growth factor enriched extracellular milieu evokes hepatocyte de-differentiation paralleled by a rapid c-Met increase on the cell surface. Western blot data show down-regulation of the intracellular c-Met content. Collectively, these suggest a rapid c-Met translocation from the cytoplasm to the plasma membrane. Remarkably, enhanced c-Met presentation was not coupled with enhanced responsiveness to HGF. We speculate that up-regulation of c-Met, which indeed takes place during the development of fibrosis/cirrhosis, might induce a negative feedback mechanism which blocks outside-in signalling. Presumably, this process was caused in conjunction with an increased HGF level at the inflammatory site, and the c-Met non-responsiveness seems to protect hepatocytes from a permanent over-stimulation by HGF. Novel experiments truly present evidence of a negative feedback regulation in which c-Met activation leads to transcriptional induction of the Notch pathway which, in turn, limits HGF activity through repression of c-Met (20).

Therefore, when discussing the therapeutic potential of HGF, it should be considered that c-Met is able to self-tune its own activity. Consequently, long-term application of HGF to treat cirrhosis might possibly evoke drug resistance. In this context, we restate that addition of bile salts to our culture system delayed the process of hepatocyte de-differentiation and c-Met elevation, whereby tauroursodeoxycholic acid demonstrated higher efficacy than ursodeoxycholic acid. Bile salts have already been shown to slow down the progression of primary biliary cirrhosis and improve a number of other cholestatic disorders (21). Also relevant is the study of Caglieres et al (22), which reported that treatment of tauroursodeoxycholic acid improved the biochemical parameters of cytolysis and cholestasis and maintained the functional stability of end-stage cirrhotic patients awaiting liver transplantation. Though the underlying mechanism is still not clear, there is 
A

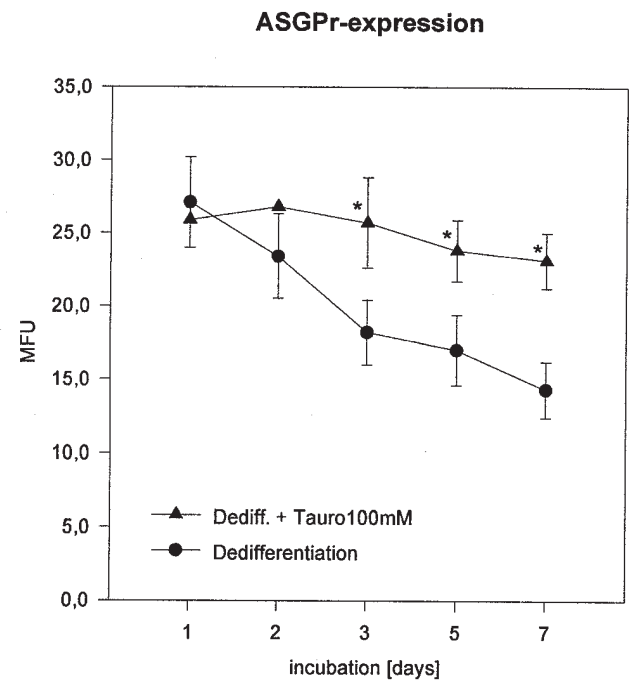

C

ASGPr-expression

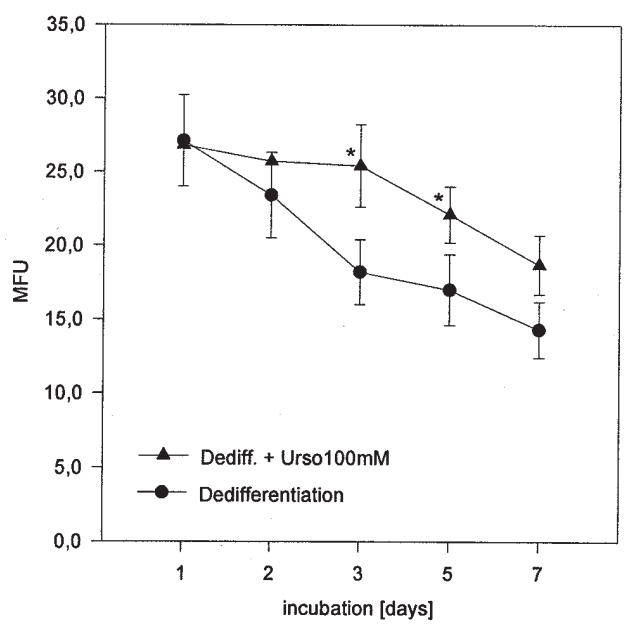

B

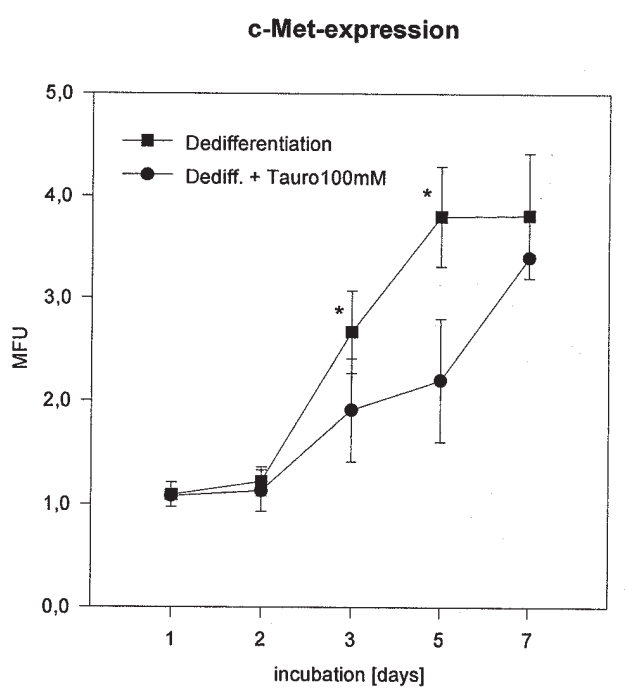

D

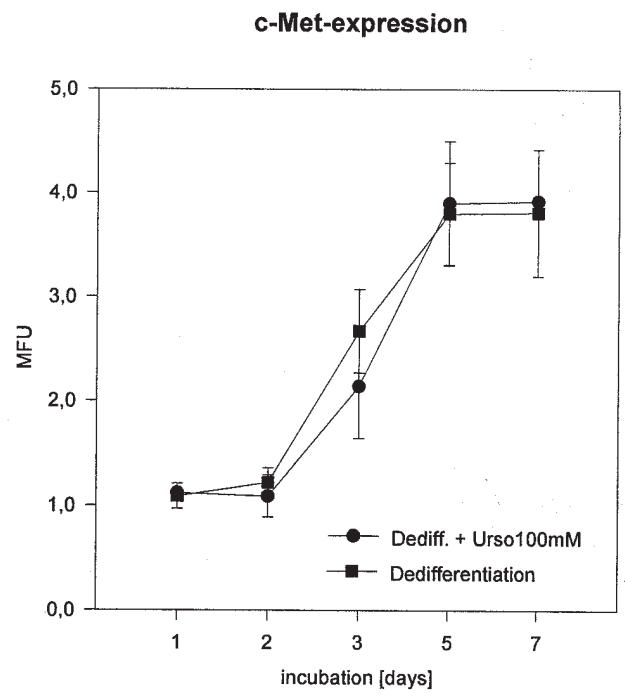

Figure 5. Influence of tauroursodeoxycholic acid (A and B) or ursodeoxycholic acid (C and D) on ASGPr- and c-Met surface expression. Hepatocytes were seeded on a two-dimensional collagen matrix and grown in de-differentiation medium, supplemented with 100 mM tauroursodeoxycholic acid. Surface receptor level was detected by flow cytometry and expressed as mean fluorescence units (MFU). Values were compared to those evaluated on hepatocytes grown in de-differentiation medium alone (control). Figures represent mean \pm SD of $n=6$ experiments which had been carried out on days $1,3,5$ and 7 after plating. * Statistically significant differences to controls.

evidence that tauroursodeoxycholic acid is responsible for receptor tyrosine kinase activation and enhanced signalling down the ERK1/2 and AKT pathways (23). Rao and coworkers identified the epidermal growth factor receptor as a possible target of tauroursodeoxycholic acid (24). Our experiments identify the c-Met receptor. Although it has not yet been clearly proven, we speculate that tauroursodeoxycholic acid might (partially) revert c-Met non-responsiveness, either by re-activating the receptor or by activating alternate pathways.

In addition to alterations in the extracellular milieu, disorganization of the normal liver architecture also contributes to changes of c-Met. Our in vitro system indicates that embedding the hepatocytes within a three-dimensional matrix stabilizes c-Met activity and keeps the c-Met expression level constant. Our experimental observation correlated with the study of Tomita et al (25) who reported that the development of fibrosis in alcoholic liver diseases and break down of the liver architecture was accompanied by a down-regulation of c-Met activity.

In an earlier publication, we demonstrated that degradation of the extracellular liver matrix led to qualitative and quantitative alterations in the intermediate filament pattern of human hepatocytes. These alterations included reduced intracellular filament coordination, enhanced expression of cytokeratins 8 
A

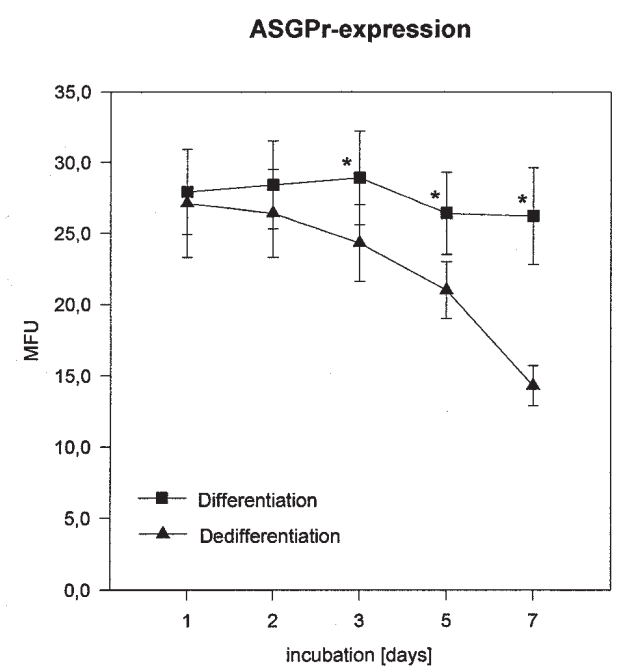

B

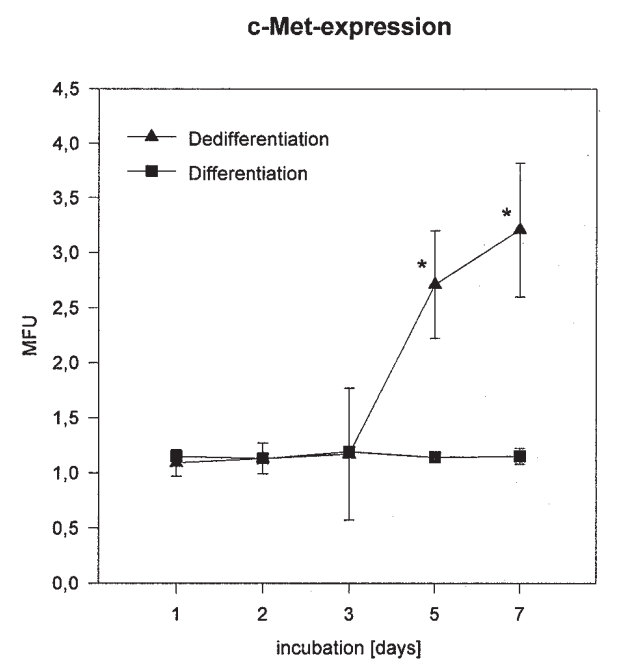

Figure 6. Influence of cell geometry on receptor expression. Hepatocytes were cultivated in a three-dimensional collagen sandwich either in differentiation medium (D) or in de-differentiation medium (DeD) representing cirrhotic conditions. The surface receptor level was detected by flow cytometry and expressed as mean fluorescence units (MFU). Mean \pm SD, $(n=6)$. Fluorometry was carried out on days 1, 3, 5 and 7 after plating. * Statistically significant differences.

\section{Three-dimensional culture system}

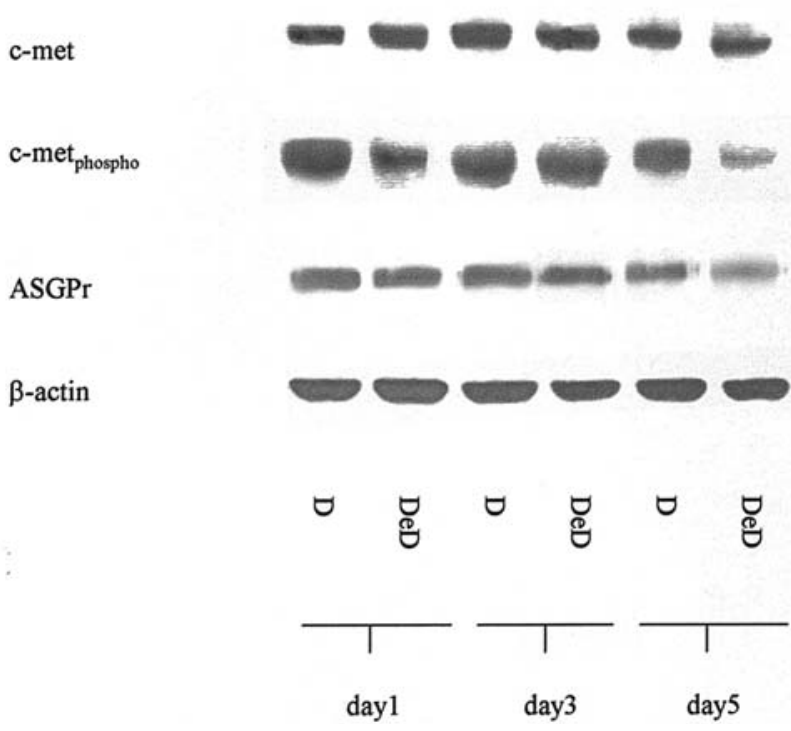

Figure 7. Influence of cell geometry on receptor content and c-Met activity. Hepatocytes were incubated within a three-dimensional collagen gel in chemically defined differentiation medium or in de-differentiation medium representing cirrhotic conditions. The protein content was analyzed on day 1,3 or 5 after plating the hepatocytes. D, cultivation in differentiation medium; DeD, cultivation in de-differentiation medium. B-actin served as the internal control. The figure shown is re-presentative of three separate experiments.

and 18, and de novo synthesis of cytokeratins 7 and 19 and vimentin (16). It seems likely that destruction of the liver matrix changes the initial hepatocyte morphology, polarity and receptor equipment. Not only growth factor receptors should be considered as sensitive membrane elements; distribution of F-actin, E-cadherin, and apical and lateral membrane proteins also depend on hepatocellular architecture $(26,27)$.

We assume that the loss of cell geometry caused by degradation of the extracellular liver matrix, changes of their chemical composition and/or their molecular organization switches c-Met from HGF-sensitive to HGF-insensitive. Modifications of further membrane receptors as well as intracellular structures might accelerate the process of hepatocyte de-differentiation. Consequently, therapeutic modulation of the liver matrix might re-sensitize the c-Met receptor. However, pharmacological intervention should not only include the prevention of excessive collagen production $(28,29)$ but also the application of matrix proteins to re-establish the physiological matrix composition. Fibronectin administration has already been shown to prevent endotoxin-induced liver injury after partial hepatectomy in rats (30). Exogenous administration of high molecular weight hyaluronan influenced liver injury induced by administration of concanavalin A (Con A) or Dgalactosamine/lipopolysaccharide (GalN/LPS) and cytokine production in mice (31). Based on an in vitro assay, we reported that enrichment of the culture medium with fluid matrix proteins stabilized hepatocyte cultures and delayed de-differentiation events (32).

In conclusion, our results demonstrate that cirrhosis is accompanied by an up-regulation of c-Met. However, c-Met receptors present at the hepatocyte cell surface remain insensitive to soluble HGF. This phenomenon might be caused by excessive HGF production and receptor over-stimulation. The switch from physiological to pathological cell morphology may contribute to a distinct blockade of c-Met dependent signals. Both events should be considered when establishing HGF-based therapy as a treatment for cirrhosis. 


\section{References}

1. Hernández-Muñoz R, Diaz-Muñoz M, Suárez-Cuenca S, Trejo-Solis T, Lopez V, Sanchez-Sevilla L, Yanez L and De Sanchez VC: Adenosine reverses a preestablished CCl4-induced micronodular cirrhosis through enchancing collagenolytic activity and stimulating hepatocyte cell proliferation in rats. Hepatology 34: 677-687, 2001

2. Birchmeier $\mathrm{C}$ and Gherardi E: Developmental roles of $\mathrm{HGF} / \mathrm{SF}$ and its receptor, the c-Met tyrosine kinase. Trends Cell Biol 8: 404-409, 1998.

3. Matsumoto K and Nakamura T: Emerging multipotent aspects of hepatocyte growth factor. J Biochem 119: 591-600, 1996.

4. Ishiki Y, Ohnishi H, Muto Y, Matsumoto K and Nakamura T: Direct evidence that hepatocyte growth factor is a hepatotrophic factor for liver regeneration and has a potent antihepatitis effect in vivo. Hepatology 16: 1227-1235, 1992.

5. Yasuda H, Imai E, Shiota A, Fujise N, Morinaga T and Higashio K: Anti-fibrogenic effect of a deletion variant of hepatocyte growth factor on liver fibrosis in rats. Hepatology 24: 636-642, 1996.

6. Matsuda Y, Matsumoto K, Yamada A, Ichida T, Asakura H, Komoriya Y, Nishiyama E and Nakamura T: Preventive and therapeutic effects in rats of hepatocyte growth factor infusion on liver fibrosis/cirrhosis. Hepatology 26: 81-89, 1997.

7. Ueki T, Kaneda Y, Tsutsui H, Nakanishi K, Sawa Y, Morishita R, Matsumoto K, Nakamura T, Takahashi H, Okamoto E and Fujimoto J: Hepatocyte growth factor gene therapy of liver cirrhosis in rats. Nat Med 5: 226-230, 1999.

8. Kim WH, Matsumoto K, Bessho K and Nakamura T: Growth inhibition and apoptosis in liver myofibroblasts promoted by hepatocyte growth factor leads to resolution from liver cirrhosis. Am J Pathol 166: 1017-1028, 2005.

9. Xue F, Takahara T, Yata Y, Kuwabara Y, Shinno E, Nonome K, Minemura M, Takahara S, Li X, Yamato E and Watanabe A: Hepatocyte growth factor gene therapy accelerates regeneration in cirrhotic mouse livers after hepatectomy. Gut 52: 694-700, 2003.

10. Andiran F, Ayhan A, Tanyel FC, Abbasoglu O and Sayek I: Regenerative capacities of normal and cirrhotic livers following $70 \%$ hepatectomy in rats and the effect of $\alpha$-tocopherol on cirrhotic regeneration. J Surg Res 89: 184-188, 2000.

11. Kawasaki S, Imamura H, Bandai Y, Sanjo K and Idezuki Y: Direct evidence for the intact hepatocyte theory in patients with liver cirrhosis. Gastroenterology 102: 1351-1355, 1992.

12. Hashimoto $\mathrm{M}$ and Watanabe G: Functional capacity of the cirrhotic liver after partial hepatectomy in the rat. Surgery 126 : 541-547, 1999.

13. Kaido T, Oe H, Yoshikawa A, Okajima A and Imamura M: Expressions of molecules associated with hepatocyte growth factor activation after hepatectomy in liver cirrhosis. Hepatogastroenterology 51: 547-551, 2004.

14. Cramer T, Schuppan D, Bauer M, Pfander D, Neuhaus P and Herbst $\mathrm{H}$ : Hepatocyte growth factor and c-Met expression in rat and human liver fibrosis. Liver Int 24: 335-344, 2004.

15. Ise H, Nikaido T, Negishi N, Sugihara N, Suzuki F, Akaide T and Ikeda U: Effective hepatocyte transplantation using rat hepatocytes with low asialoglycoprotein receptor expression. Am J Pathol 165: 501-510, 2004.

16. Blaheta RA, Kronenberger B, Woitaschek D, Auth MK, Scholz M, Weber S, Schuldes H, Encke A and Markus BH: Dedifferentiation of human hepatocytes by extracellular matrix proteins in vitro: quantitative and qualitative investigation of cytokeratin $7,8,18$, 19 and vimentin filaments. J Hepatol 28: 677-690, 1998.

17. Auth MK, Boost KA, Leckel K, Beecken WD, Engl T, Jonas D, Oppermann E, Hilgard P, Markus BH, Bechstein WO and Blaheta RA: Controlled and reversible induction of differentiation and activation of adult human hepatocytes by a biphasic culture technique. World J Gastroenterol 11: 2080-2087, 2005.
18. Pani G, Fusco S, Colavitti R, Borrello S, Maggiano N, Cravero AA, Farre SM, Galeotti T and Koch OR: Abrogation of hepatocyte apoptosis and early appearance of liver dysplasia in ethanol-fed p53-deficient mice. Biochem Biophys Res Commun 325: 97-100, 2004.

19. Lemmer ER, De la Motte Hall P, Omori N, Omori M, Shephard EG, Gelderblom WC, Cruse JP, Barnard RA, Marasas WF, Kirsch RE and Thorgeirsson SS: Histopathology and gene expression changes in rat liver during feeding of fumonisin B1, a carcinogenic mycotoxin produced by Fusarium moniliforme. Carcinogenesis 20: 817-824, 1999.

20. Stella MC, Trusolino L, Pennacchietti S and Comoglio PM: Negative feedback regulation of Met-dependent invasive growth by Notch. Mol Cell Biol 25: 3982-3996, 2005.

21. Paumgartner G and Beuers U: Mechanisms of action and therapeutic efficacy of ursodeoxycholic acid in cholestatic liver disease. Clin Liver Dis 8: 67-81, 2004.

22. Caglieris S, Giannini E, Dardano G, Mondello L, Valente U and Testa R: Tauroursodeoxycholic acid administration as adjuvant therapy in cirrhotic patients on transplantation waiting lists. Hepatogastroenterology 47: 1045-1047, 2000.

23. Fang Y, Han SI, Mitchell C, Gupta S, Studer E, Grant S, Hylemon PB and Dent P: Bile acids induce mitochondrial ROS, which promote activation of receptor tyrosine kinases and signaling pathways in rat hepatocytes. Hepatology 40: 961-971, 2004

24. Rao YP, Studer EJ, Stravitz RT, Gupta S, Qiao L, Dent P and Hylemon PB: Activation of the Raf-1/MEK/ERK cascade by bile acids occurs via the epidermal growth factor receptor in primary rat hepatocytes. Hepatology 35: 307-314, 2002.

25. Tomita K, Azuma T, Kitamura N, Nishida J, Tamiya G, Oka A, Inokuchi S, Nishimura T, Suematsu M and Ishii H: Pioglitazone prevents alcohol-induced fatty liver in rats through up-regulation of c-Met. Gastroenterology 126: 873-885, 2004

26. Moghe PV, Berthiaume F, Ezzell RM, Toner M, Tompkins RG and Yarmush ML: Culture matrix configuration and composition in the maintenance of hepatocyte polarity and function. Biomaterials 17: 373-385, 1996.

27. Michalopoulos GK, Bowen WC, Zajac VF, Beer-Stolz D, Watkins S, Kostrubsky V and Strom SC: Morphogenetic events in mixed cultures of rat hepatocytes and nonparenchymal cells maintained in biological matrices in the presence of hepatocyte growth factor and epidermal growth factor. Hepatology 29: 90-100, 1999.

28. Cheng K, Ye Z, Guntaka RV and Mahato RI: Biodistribution and hepatic uptake of triplex-forming oligonucleotides against type alpha1(I) collagen gene promoter in normal and fibrotic rats. Mol Pharm 2: 206-217, 2005.

29. Stefanovic L, Stephens CE, Boykin D and Stefanovic B: Inhibitory effect of dicationic diphenylfurans on production of type I collagen by human fibroblasts and activated hepatic stellate cells. Life Sci 76: 2011-2026, 2005.

30. Saito T, Kwon AH, Qiu Z, Tsuchiya H, Tsuji K and Kamiyama Y: Protective effect of fibronectin for endotoxin-induced liver injury after partial hepatectomy in rats. J Surg Res 124: 79-84, 2005 .

31. Nakamura K, Yokohama S, Yoneda M, Okamoto S, Tamaki Y, Ito T, Okada M, Aso K and Makino I: High, but not low, molecular weight hyaluronan prevents T-cell-mediated liver injury by reducing proinflammatory cytokines in mice. $\mathrm{J}$ Gastroenterol 39: 346-354, 2004

32. Blaheta RA, Kronenberger B, Woitaschek D, Schick C, Oppermann E, Auth MK, Strain AJ, Weber S, Encke A and Markus BH: Interference of soluble mediators into liver matrix triggered dedifferentiation of human hepatocytes. Transplant Proc 31: 502-504, 1999. 